Türkiye Jeoloji Bülteni
Geological Bulletin of Turkey
$62(2019) 167-180$
doi: 10.25288 tj. .559947

\title{
02.03.2017 ve 24.04.2018 Samsat (Adıyaman) Depremleri ve Bölgesel Sismotektonik İçindeki Önemi
}

02.03.2017 and 24.04.2018 Samsat (Adiyaman) Earthquakes and Their Importance in Regional Seismotectonics

\author{
Orhan Tatar' $^{1}$, Fikret Koçbulut ${ }^{1} \mathbb{D}$, Ali Polat ${ }^{2}$, Mehmet Demirel ${ }^{1} \mathbb{D}$ \\ ${ }^{1}$ Sivas Cumhuriyet Üniversitesi, Jeoloji Mühendisliği Bölümü, 58140 Sivas \\ 2 Sivas Il Afet ve Acil Durum Müdürlüğ̈̈, 58040 Sivas
}

Geliş/Received : 28.03.2019 • Düzeltilmiş Metin Geliş/Revised Manuscript Received : 25.04.2019 • Kabul/Accepted : 29.04 .2019 • Bask1/Printed : 08.05.2019 Araşstrma Makalesi/Research Article Türkiye Jeol. Bül./Geol. Bull. Turkey

Öz: Bu çalışmada, 2 Mart 2017 tarihinde saat 14.06'da Adıyaman ili Samsat ilçesine 2.5 km uzaklıkta, yerin yaklaşık $10 \mathrm{~km}$ derinliğinde meydana gelen $5.5 \mathrm{Mw}$ büyüklügündeki depremin bölgede yüzey deformasyonları oluşturup oluşturmadığı, Yapay Açıklık Radar İnterferometrisi (InSAR) yöntemi ve arazi gözlemleriyle incelenmiştir. Deprem öncesi ve deprem sonrasına ait Sentinel-1A uydusunun iki yapay açıklık radarı (SAR) görüntüsü analiz edilerek oluşturulan interferogramdan deformasyon belirlenmeye çalışılmıştır. Interferogramın değerlendirilmesi sonucunda bölgede uydu bakış yönünde (LoS) yaklaşık $2.5 \mathrm{~cm}$ civarında bir yüzey deformasyonunun meydana geldiği gözlenmiştir. Bu deformasyon daha çok Samsat ilçesi yakın kuzeydoğusunda yoğunlaşmıştır. Bölgede depremin hemen sonrasında yapılan ayrıntılı saha incelemeleri sonucunda ise herhangi bir yüzey kırığının oluşmadığı, buna karşın bazı alanlarda yersel çatlaklar şeklinde yüzey deformasyonlarının geliştiği saptanmıştır. Depremin, Samsat İlçesinin yaklaşık $5 \mathrm{~km}$ kuzeyinden geçen ve TPAO tarafından Samsat Fayı olarak adlandırılan fay üzerinde geliştiği anlaşılmaktadır. Ana şok sonrası bölgede meydana gelen 400'ü aşkın arţ̧ı sarsıntının kabaca K40-50B gidişli bir çizgisellik üzerinde yoğunlaştığı görülmektedir. Sahada yapılan gözlemlerde de hasar dağılımının özellikle bu hat boyunca geliştiği dikkat çekicidir.

Anahtar Kelimeler: Adıyaman, aktif fay, Samsat depremi, yüzey deformasyonu.

\begin{abstract}
In this study, Synthetic Aperture Radar Interferometry (InSAR) method is used together with field observations to determine whether surface deformations occur in the region after the 5,5 Mw (AFAD) Samsat Earthquake occurred at a distance of $2.5 \mathrm{~km}$ from the Samsat district of Adiyaman province on 2 March 2017. We attempted to determine the deformation of the interferogram created by analyzing two Synthetic Aperture Radar (SAR) images of the Sentinel-1A fit before and after the earthquake. As a result of the evaluation of the interferogram, a surface deformation of about $2.5 \mathrm{~cm}$ in the satellite view direction/Line of Sight (LoS) was observed in the region. This deformation is mostly concentrated in the northeast of Samsat town. As a result of the detailed field investigations made immediately after the earthquake in the region, no surface rupture occurred but surface deformations in the form of local and discontinous fissures developed in some areas. It is understood that the Earthquake developed on a fault passing through about $5 \mathrm{Km}$ North of Samsat and named as Samsat Fault by TPAO. It appears that more than 400 aftershocks following the main shock in the region concentrate roughly on a N40-50W lineament. It is noteworthy that in the observations made in the field, the distribution of the damage has also developed along this line in particular.
\end{abstract}

Keywords: Adlyaman, active fault, Samsat earthquake, surface deformation.

\footnotetext{
*Yazışma / Correspondence: orhantatar@cumhuriyet.edu.tr
}

(C) 2019 JMO Her hakkı saklıdır/All rights reserved http://tjb.jmo.org.tr http://dergipark.gov.tr/tjb 


\section{GíRiş}

2 Mart 2017 tarihinde yerel saat ile 14.07'de AFAD verilerine göre merkez üssü Adiyaman iline bağlı Samsat ilçesi Uzuntepe Köyü olan Mw:5.5 büyüklüğünde bir deprem olmuştur. $\mathrm{Bu}$ deprem sonrasında 30 civarında vatandaş yaralanmış, Samsat ilçe merkezi ve civar köylerde hasar meydana gelmiştir. Bu depremden bir y1lı aşkın bir süre sonra 24 Nisan 2018 tarihinde yerel saatle 03.34'de yine aynı bölgede bu kez merkez üssü Kırmacık Köyü olan Mw:5.3 büyüklügüünde deprem meydana gelmiştir. Deprem sonucunda 35 kişi hafif yaralanmış, 2 bina yıkılmış, bazı köylerdeki binalarda hafif ve orta boyutta hasar oluşmuştur. Depremler başta Adıyaman kent merkezi ve ilçeleri olmak üzere Doğu ve Güneydoğu Anadolu'da birçok yerleşim yerinde hissedilmiştir. Her iki deprem sonrasında bölgede çok sayıda artçı sarsıntılar meydana gelmiştir. 2 Mart 2017 tarihinde meydana gelen deprem sonrasında bölgede yapılan saha çalışmaları sonucunda yer yer yüzeyde çatlakların oluştuğu ancak her iki deprem sonucunda bir yüzey faylanması gerçekleşmediği gözlenmiştir.

Güneydoğu Anadolu Bölgesinde Firat Nehri kıyısında bulunan Samsat İlçesi yörede tarihi en eskiye dayanan yerleşim yerlerinden birisidir. Kâhta Çayı ile Göksu Çayları arasındaki düzlüğün Fırat Nehri kıyısındaki en geniş kesiminde yer alan Samsat, Adıyaman'ın 1954 yılında il merkezi olması nedeniyle, ilçeye dönüşerek Adıyaman'a bağlanmıştır. Eski Samsat olarak adlandırılan bu yerleşim yeri 1987 yılında Atatürk Barajı sularının yükselmesiyle birlikte sular altında kalmış ve ilçe 1988 tarihinde tamamen boşaltılarak bugünkü yerine taşınmıştır (Bakırıı 1997).

\section{SAMSAT VE ÇEVRESININ JEOLOJISİ}

İnceleme alanı en geniş anlamda Doğu Anadolu Sıkışma Bölgesi (DASB) içinde yer almaktadır. En güneydeki bölgeyi Bitlis Bindirme Kuşağı oluşturur. Bu kuşak, Arap plakası ile Avrasya plakası arasında yer alan Neotetis in güney kolunun Serravaliyen sonunda kapanması sonucu meydana gelmiştir. Bitlis Bindirme Kuşağ1, Kahramanmaraş ile Yüksekova arasında, güneye yönelmiş ters faylardan meydana gelir. Bu zon, $1500 \mathrm{~km}$ uzunlukta olup $60 \mathrm{~km}$ genişlikte bir bölgeyi oluşturur (Perinçek 1978; Yılmaz vd. 1992; Gülkan vd. 1993). Şengör ve Y1lmaz (1981) bu kuşağ1 Bitlis Yitim Zonu olarak adlandırmış ve bu zonun Orta Miyosen-Üst Miyosen (Langiyen-Serravaliyen) boyunca Arap ve Avrasya Plakalarının birbirlerinin altına dalması sonucunda oluştuğunu belirtmişlerdir. $\mathrm{Bu}$ zon boyunca oluşan dalma-batma hareketi bölgenin topoğrafik olarak yükselmesi ve dağ oluşumuna sebep olmuştur. Bu zon güncel olarak aktivitesini devam ettirmektedir. Bunun sonucu olarak Doğu Anadolu Bölgesi sıkışmaya devam etmekte, farklı alanlarda oluşan aktif bindirme fayları boyunca değişik büyüklükte depremler meydana gelmektedir. 1975 Lice ve 2011 Van Depremleri bindirme faylarından kaynaklanan depremlere en iyi örneklerdir (Gökçe vd. 2014).

Torid Tektonik Birliği içerisinde yer alan ve Türkiye'nin önemli tektonik yapılarından olan Güneydoğu Anadolu Bindirme Kuşağı ve Doğu Anadolu Fay Sistemi gibi iki önemli unsuru içerisinde bulunduran Adıyaman ve yakın çevresi çeşitli araştırmacılar tarafindan incelenmiştir. Türkiye'nin önemli petrol sahalarının yörede veya yakın çevresinde bulunması, bölge jeolojisinin önemini daha da arttırmıştır.

İnceleme alanı, Güney Doğu Anadolu Bindirme Kuşağı ile Toros Orojenik Kuşağ sınırında bulunmaktadır (Ketin,1966). Güneydoğu Anadolu Orojenik Kuşağ1, kuzeyde Toros, güneyde ise Arap platformları ile sinırlanan Neotetis'in güney kolunun Geç Kretase-Miyosen zaman aralığında kapanması sırasındaki jeolojik olaylar sonucunda gelişmiştir. Bu kuşağın evrimi, özellikle napların Geç Kretase Miyosen zaman aralığında göreceli olarak güneye, Arap levhasına 
doğru hareketini içermektedir (Yılmaz, 1993; Y1lmaz vd. 1993). Güneydoğu Anadolu Orojenik Kuşağ1 yaklaşık D-B uzanımlı ve birbirlerinden kuzeye eğimli ana bindirme düzlemleri ile ayrılan üç farklı tektonik birlikten oluşmaktadır. $\mathrm{Bu}$ tektonik birlikler kuzeyden güneye doğru Nap zonu, Yı̆̆ışım Prizması ve Arap platformu'dur. Kretase ile Miyosen sonunda oluşan ve bölgeye allokton birimlerin yerleşmesini sağlayan yoğun tektonik faaliyet, aynı dönemde denizel çökel gelişimine ve çanakların kapanmasına neden olmuştur. Allokton birimler, çekim kaymaları ve sürüklenim örtüleri olarak Üst Miyosen sonunda bugünkü konumlarını kazanmışlardır (Yılmaz, 1990 ve 1993; Y1lmaz vd. 1993).

\section{SAMSAT (ADIYAMAN) VE CIVARININ SISMOTEKTONIK ÖZELLIKKLERİ}

Samsat İlçesi ve bağlı olduğu Adıyaman ve çevresi Arabistan ve Arap levhalarının çarpışması sonucu oluşan ve halen aktivitesini sürdüren Güneydoğu Anadolu Bindirme Zonu ile sol yanal doğrultu atımlı Doğu Anadolu Fay Zonu arasında bulunan ve bindirme tektoniğinin en iyi gözlendiği alanlardan birisidir. Bindirme ve sol yanal doğrultu atımlı fay sistemlerinin yanı sıra Samsat İlçesi güneyinde yer alan Bozova Fayı Yenilenmiş Türkiye Diri Fay Haritası'nda (Duman vd. 2012, 2013) Kuvaterner Fayı olarak nitelendirilmiştir. Bu fay Türkiye Sismotektonik Haritası'nda 50 km uzunlukta, ters bileşenli sağ yanal doğrultu atımlı fay şeklinde tanımlanmıştır (Duman vd. 2017).

Doğu-Güneydoğu Anadolu Bölgesi, dünyanın önemli deprem kuşaklarından olan Alp-Himalaya orojenik kuşağı içindeki Bitlis Kenet Zonu ön cephesinde yer alır. Bu kenet kuşağı Güneydoğu Anadolu Bindirme Zonu olarak bilinir. SiirtHakkâri-Cizre arasında bindirme zonunun genişliği K-G yönünde 100 km'den fazladır. $\mathrm{Bu}$ alanda zon içinde birbirine koşut çok sayıda bindirme fayı, kıvrım ve sağ yönlü doğrultu atımlı diri faylar bulunur. Adıyaman ve çevresinin ana tektonik yapılarını gösterir sismotektonik harita Şekil 1 ve 2'de verilmiştir.

Güneydoğu Anadolu Bindirme Kuşağı Hakkari'den Kahramanmaraş civarına kadar devam eden ve orada Doğu Anadolu Fay Zonu (DAFZ) ile kesilen bir bindirme fayıdır. Kesilme yerinde bindirmenin $25 \mathrm{~km}$. lik bir atımı vardır. Çalışma alanı ve yakın civarı en geniş anlamda Doğu Anadolu Sıkışma Bölgesi içinde yer almaktadır. Doğu Anadolu Sıkışma Bölgesi içinde kuzeyden güneye doğru, Kuzeydoğu Anadolu Fay Zonu, Kuzey Anadolu Fay Zonu'nun Karlıova'nın doğusunda yer alan sağ ve sol yönlü doğrultu atımlı fayları ile Bitlis Bindirme Kuşağı bulunur. İnceleme alanının da içinde yer aldığ en güneydeki bölgeyi Bitlis Bindirme Kuşağ1 oluşturur. Samsat ilçesi ve civarında bulunan en önemli deprem kaynakları Doğu Anadolu Fay Zonu'na ait Pütürge ve Erkenek segmentleri, Güneydoğu Anadolu Bindirme Zonu'na ait Gerger segmenti ile güneyinde bulunan Bozova Fayıdır (Herece 2008; Duman vd. 2013, Şekil 1 ve 2).

Bölgede tarihsel ve aletsel dönemde depremler meydana gelmiştir. Bölgedeki depremler iki ana kaynaktan oluşmaktadır. Samsat ilçesi kuzeykuzeybatısında bulunan Doğu Anadolu Fay Zonu ile Güneydoğu Anadolu Bindirme Zonu üzerinde tarihsel dönemlerde yıkıcı depremler meydana gelmiştir. Tarihsel dönemde MÖ 1800-MS 1900 y1lları arasında Adıyaman'da herhangi bir tarihsel deprem bulunmamakla beraber, yakınında bulunan Kahramanmaraş, Elazı̆̆g, Malatya gibi illerde yıkıcı depremler meydana gelmiştir (İmamoğlu ve Çetin 2007). Doğu Anadolu Fay Zonu'na ait Pütürge ve Erkenek segmentleri Samsat ilçesinin kuş uçusu 50-60 km kuzey-kuzeydoğusundan geçmektedir. İki segment arasında ise Yarpuzlu sıkıştıran büklümü yer almaktadır (Duman vd. 2013). Yörenin tarihsel deprem etkinliğine bakıldığında, 6.7 büyüklüğündeki 1875 ve 6.8 büyüklüğündeki 1905 depremlerinin Pütürge segmenti üzerinde geliştiği düşünülmektedir (Ambraseys 1988). Erkenek segmenti üzerinde 
ise yüzey faylanması oluşturan en son deprem 7.2 büyüklüğünde, 1893 yılında meydana gelmiştir (Ambraseys, 1988, Ambraseys ve Jackson 1998). Aletsel dönemde ise Samsat ilçesine en yakın deprem, Adıyaman kuzeyinde Doğu Anadolu Fay Zonu üzerinde 1964 y1lında meydana gelen $\mathrm{M}=6.0$ büyüklüğündeki Aksu-Sincik depremidir. $\mathrm{Bu}$ depremin dişında 1981 ve 2010 yıllarında Gerger ilçesinde $\mathrm{M}=5.0$ ve $\mathrm{M}=4.7$ büyüklüklerinde depremler meydana gelmiştir. Sbeinati vd. (2005) tarafindan hazırlanan ve Suriye'de 1365 $\mathrm{BC}$ ve $1900 \mathrm{AD}$ arasında meydana gelen yıkıcı depremlerin incelendiği çalışmada 1114 yılı Kasım ayında Samsat, Urfa ve Harran'1 etkileyen 9 şiddetinde bir depremden söz edilmektedir. Aletsel büyüklüğü 7.7'ye karş1lık gelen ve yerin $40 \mathrm{~km}$ derinliğinde oluşan bu depremin merkez üssü Kahramanmaraş civarına karşıllk gelmektedir. Deprem sonucunda Harran kalesinin yarısının yıkıldığ $1, \quad 10.000$ insanın yaşamını yitirdiği, heyelanların oluştuğu, Samsat'ın yerle bir olduğu ve birçok insanın yıkıntılar altında can verdiği belirtilmektedir. Ancak depremin diş merkezinin Sbeinati vd. (2005)'de verilen koordinatlarının Kahramanmaraş güneybatısında bir noktaya düşmesi bu depremin olasılıkla Doğu Anadolu Fay Zonu üzerinde meydana geldiğine işaret etmektedir.

2017 yılında yayımlanan Türkiye Sismotektonik Haritası'nda (Duman vd. 2017) ise Samsat İlçesi güneydoğusunda aletsel dönemde meydana gelen 6 ayrı deprem aktivitesi gösterilmiştir. $\mathrm{Bu}$ depremler 24.09.1999 ve 12.02.2012 yılları arasında meydana gelmiş olup büyüklükleri 4.1 ile 5.0 arasında değişmektedir. 2008 yılında meydana gelen 3 depremin ise odak mekanizması çözümleri sağ yanal doğrultu atımlı faylanmayı işaret etmektedir. Güneyde kalan Bozova fayı üzerinde ve yakınında ise aletsel dönemde oluşmuş 3 ayrı deprem aktivitesi bulunmaktadır. Bu depremlerin büyüklüğü 4.1-4.5 arasında olup, odak mekanizması çözümü yapılan 01.12.2012 tarihindeki 4.1 büyüklüğündeki deprem ters bileşenli sağ yanal doğrultu atımlı mekanizma sunmaktadır. Dünyanın üçüncü en büyük baraj1 olan Atatürk Barajı' nda rezervuardaki değişen su seviyelerinin depremleri tetiklediği öne sürülmektedir (Eyidoğan vd. 2010; Eyidoğan ve Geçgel 2010). Baraj gölü 1992 yılında su tutmaya başlamış, 1994 Mart ayında 530 m. Seviyesine ulaşmıştır. Eyidoğan vd. (2010), özellikle 1994 yılında, baraj gölü tam kapasiteye ulaştığı zaman, küçük büyüklükteki depremlerin sıklıkla oluşmaya başladığını belirtmiştir. Yazarlar, 2007 ve 2008 yaz ayları boyunca, barajdaki su seviyesinin yetersiz yağış nedeniyle önemli ölçüde azaldığını ve bu hızlı su seviye düşüklüğünün bölgedeki gerilimi değiştirdiğini ve 5.0 büyüklüğündeki depremin enerjinin serbest kalması sonucu oluştuğunu öne sürmüşlerdir. Atatürk Baraj Gölü havzasında meydana gelen 21.02.2008 (Mw:3.5) ve 03.09.2008 (Mw:5.0) depremlerinin su seviyesinde oluşan salınım ve azalmalardan kaynaklandığını belirten yazarlar, baraj gölünde 01.01.2007 ve 01.12.2009 yılları arasındaki su seviyesi değişimlerini incelemişlerdir. Eyidoğan ve Geçgel (2010), baraj gölünde 3.5 yıllık bir duraylı su seviyesinden sonra, ikinci büyük su azalma sürecinin 2007 Haziranında başladığını ve küçük bazı salınımlara rağmen 2009 yılı Aralık ayına kadar sürdüğünü belirtmişlerdir. $\mathrm{Bu}$ dönem içerisinde iki azalma dönemi vardır. $\mathrm{Bu}$ azalma dönemlerinde biri Ml:3.8, diğeri M1:5.2 büyüklüğünde dikkat çekici iki adet deprem tetiklenmiştir. 5.2 büyüklüğündeki deprem birçok küçük artçı sarsıntı yanı sıra büyüklükleri 4 olan iki ayrı artçı şok yaratmıştır. Baraj gölü yakınında olan bu depremlerin hepsi sığ derinliklerde meydana gelmiş ve çok az bir normal faylanma bileşeni olan sağ yanal doğrultu atımlı faylanma mekanizmasina sahiptir. Deprem aktivitesi ortalama $7 \mathrm{~km}$ derinlikte olmuştur. 


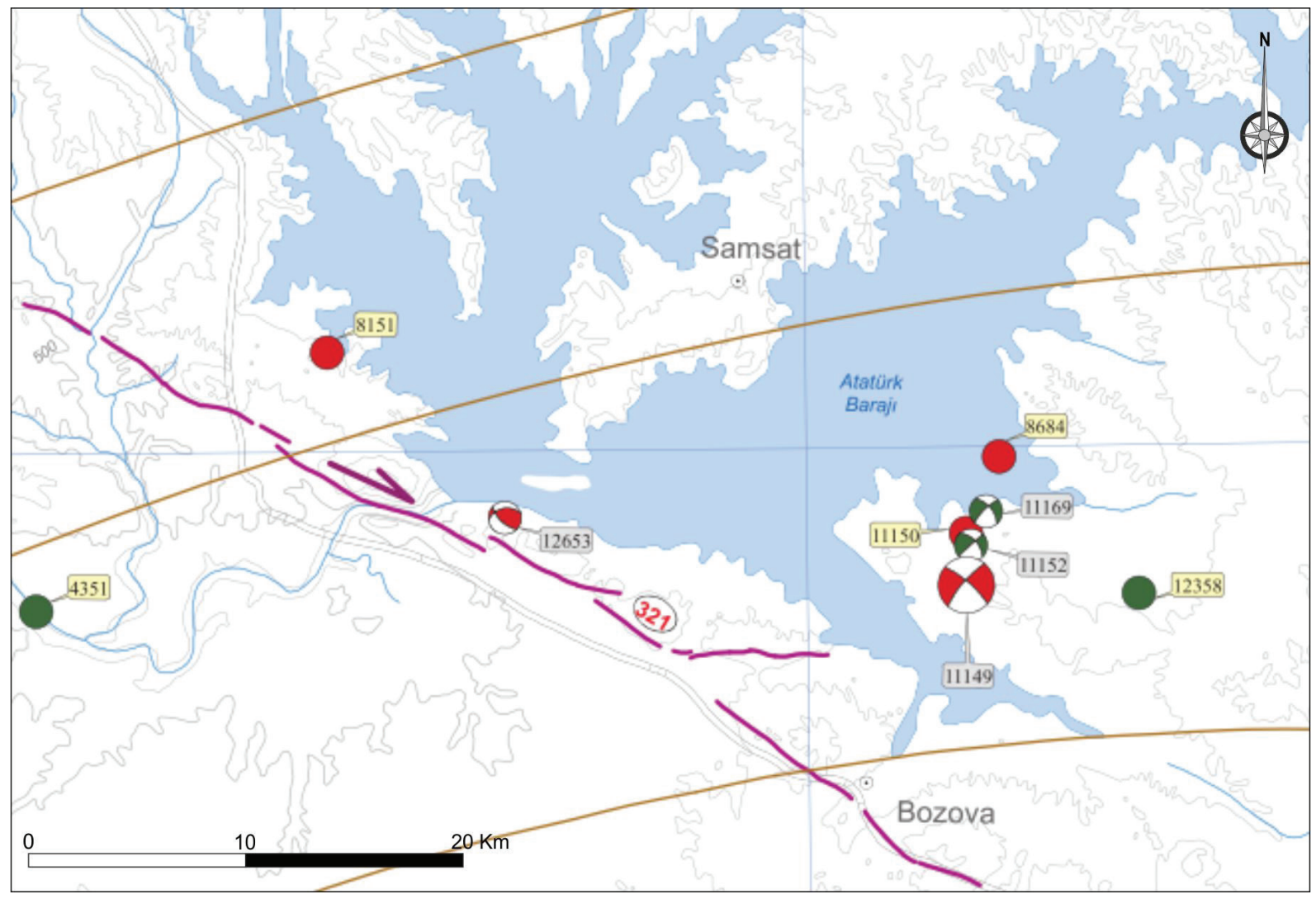

Şekil 1. Samsat ve civarında meydana gelen ve odak mekanizması çözümü yapılan depremlerin Türkiye Sismotektonik Haritası'ndaki görünümü (Duman vd. 2017).

Figure 1. The earthquakes with focal mechanism solutions occurred in and around Samsat shown in Seismotectonics Map of Turkey (Duman et al. 2017).

\section{Mart 2017 ve 24 Nisan 2018 Samsat Depremleri}

02.03.2017 tarihinde meydana gelen $\mathrm{Mw}=5.5$ büyüklüğündeki depremin merkez üssüne en yakın yerleşim yeri Samsat ilçesi kuzeyinde bulunan Uzuntepe köyüdür. Yaklaşık 11 saniye süren depremin odak derinliği ise $9.76 \mathrm{Km}$ 'dir. Depremin hemen sonrasında büyüklüğü 4.4 'e kadar ulaşan birçok artçı deprem meydana gelmiş ve bu sarsıntılar uzun süre devam etmiştir. AFAD Deprem Dairesi tarafindan yapılan odak mekanizması çözümü depremin sağ yanal doğrultu atımlı bir fay üzerinde oluştuğunu göstermektedir (Şekil 2). 2017 yılında meydana gelen depremden yaklaşık 14 ay sonra 24 Nisan 2018 tarihinde meydana gelen $\mathrm{Mw}=5.1$ büyüklüğündeki depremin odak derinliği ise $13 \mathrm{~km}$ civarında olup sı ̆g odaklı bir depremdir. Depremin merkez üssü Samsat ilçesinin güneyinde bulunan Kırmacık köyüne düşmektedir. Bu deprem sonrasında da büyüklüğü 3.6'ya kadar ulaşan çok sayıda artçı sarsıntı kaydedilmiştir. USGS, AFAD Deprem Dairesi ve B.Ü. Kandilli Rasathanesi ve Deprem Araştırma Enstitüsü gibi farklı kurumlar tarafından yapılan depremin odak mekanizması çözümü kuzeydoğuya eğimli, bir miktar ters bileşenli sağ yanal doğrultu atımlı faylanma mekanizmasını göstermektedir (Şekil 2, Tablo 1). 2 Mart 2017 ve 24 Nisan 2018 tarihlerinde meydana gelen depremlerin fay düzlemi çözümleri karşılaştırıldığında bir miktar farklılık gösterdiği anlaşılmaktadır. 2 Mart 2017 depremi sağ yanal doğrultu atımlı bir 
faylanma mekanizması gösterirken, 24 Nisan 2018 depremi ise ters bileşenli sağ yanal doğrultu atımlı faylanmayı işaret etmektedir. Her iki depremin merkez üsleri karşılaştırıldığında, 2017 depreminin merkez üssünün Samsat kuzeyine, 2018 depreminin ise Samsat güneyine düştüğü görülmektedir. Artçı sarsıntıların dağılımı her iki deprem için kabaca KB-GD gidişli bir çizgisellik üzerinde yoğunlaşmayı göstermektedir (Şekil 3). MTA tarafindan yayımlanan Yenilenmiş Türkiye
Diri Fay Haritası'nda Samsat İlçesi güneyinde yer alan ve Atatürk Baraj Gölünün güneybatı kenarını sınırlayan $\mathrm{K} 50^{\circ} \mathrm{B}$ genel gidişli, yaklaşık $50 \mathrm{Km}$ uzunluğundaki fay Bozova Fayı olarak adlandırılmıştır. $\mathrm{Bu}$ fay ters bileşenli sağ yanal doğrultu atımlı bir Kuvaterner fayı şeklinde tanımlanmıştır (Duman vd. 2012). Buna karşın Samsat yakınında MTA tarafından yenilenmiş Diri Fay Haritası Suruç paftasında tanımlanmış diri fay bulunmamaktadir.

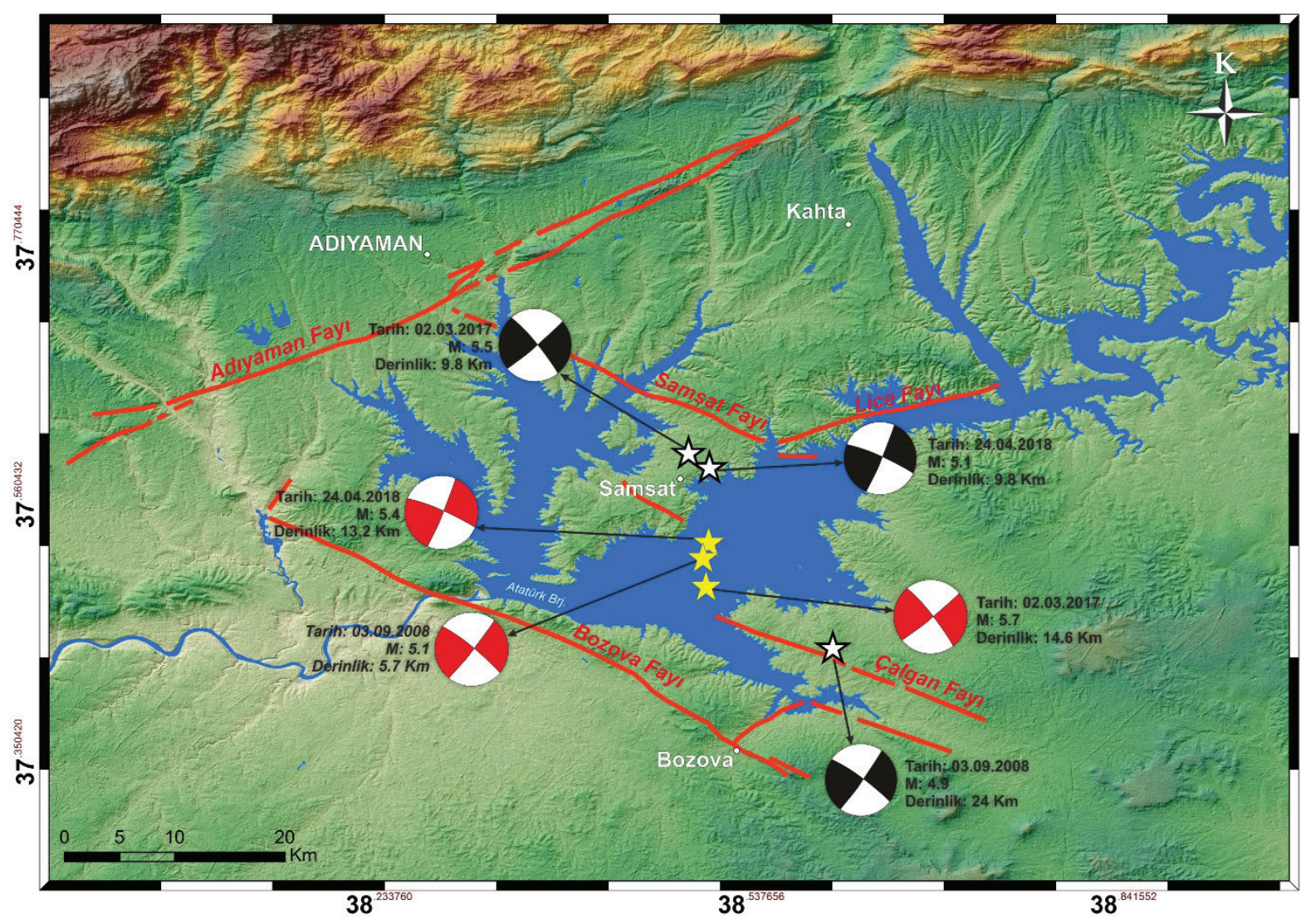

Şekil 2. Adıyaman civarının sismotektonik haritası ve 2 Mart 2017 ve 24 Nisan 2018 Samsat Depremlerine ait odak mekanizması çözümleri (Odak mekanizması çözümleri AFAD Deprem Dairesi ve B.Ü. Kandilli Rasathanesi ve Deprem Araştırma Enstitüsü'nden alınmıştır. Siyah-beyaz odak çözümleri AFAD, kırmızı-beyaz odak çözümleri B.Ü. Kandilli Rasathanesi ve Deprem Araştırma Enstitüsü'ne aittir.

Figure 2. The seismotectonic map of the Adlyaman region and the focal mechanism solutions of the Samsat Earthquakes (March 2, 2017 and April 24, 2018) were taken from the AFAD Earthquake Department (black) and Kandilli Observatory and Earthquake Research Institute (red). 
Tablo 1. 2 Mart 2017 ve 24 Nisan 2018 Samsat depremlerine ait sismik parametreler.

Table 1. Seismic parameters of 2 March 2017 and 24 April 2018 Samsat earthquakes.

\begin{tabular}{|l|l|l|l|l|l|l|}
\hline Tarih & Saat & Enlem (D) & Boylam $(\mathrm{K})$ & Derinlik $(\mathrm{Km})$ & $\begin{array}{l}\text { Büyüklük } \\
(\mathrm{Mw})\end{array}$ & Kaynak \\
\hline 02.03 .2017 & 14.07 & 37.5955 & 38.4866 & 9.76 & 5.5 & AFAD \\
\hline 02.03 .2017 & 14.07 & 37.4860 & 38.5010 & 14.6 & 5.7 & Kandilli \\
\hline 02.03 .2017 & 14.07 & 37.616 & 38.431 & 10.0 & 5.6 & USGS \\
\hline 24.04 .2018 & 03.34 & 37.5836 & 38.5036 & 9.79 & 5.1 & AFAD \\
\hline 24.04 .2018 & 03.34 & 37.5092 & 38.5033 & 14.7 & 5.3 & Kandilli \\
\hline 24.04 .2018 & 03.34 & 37.596 & 38.514 & 10.0 & 5.2 & USGS \\
\hline
\end{tabular}

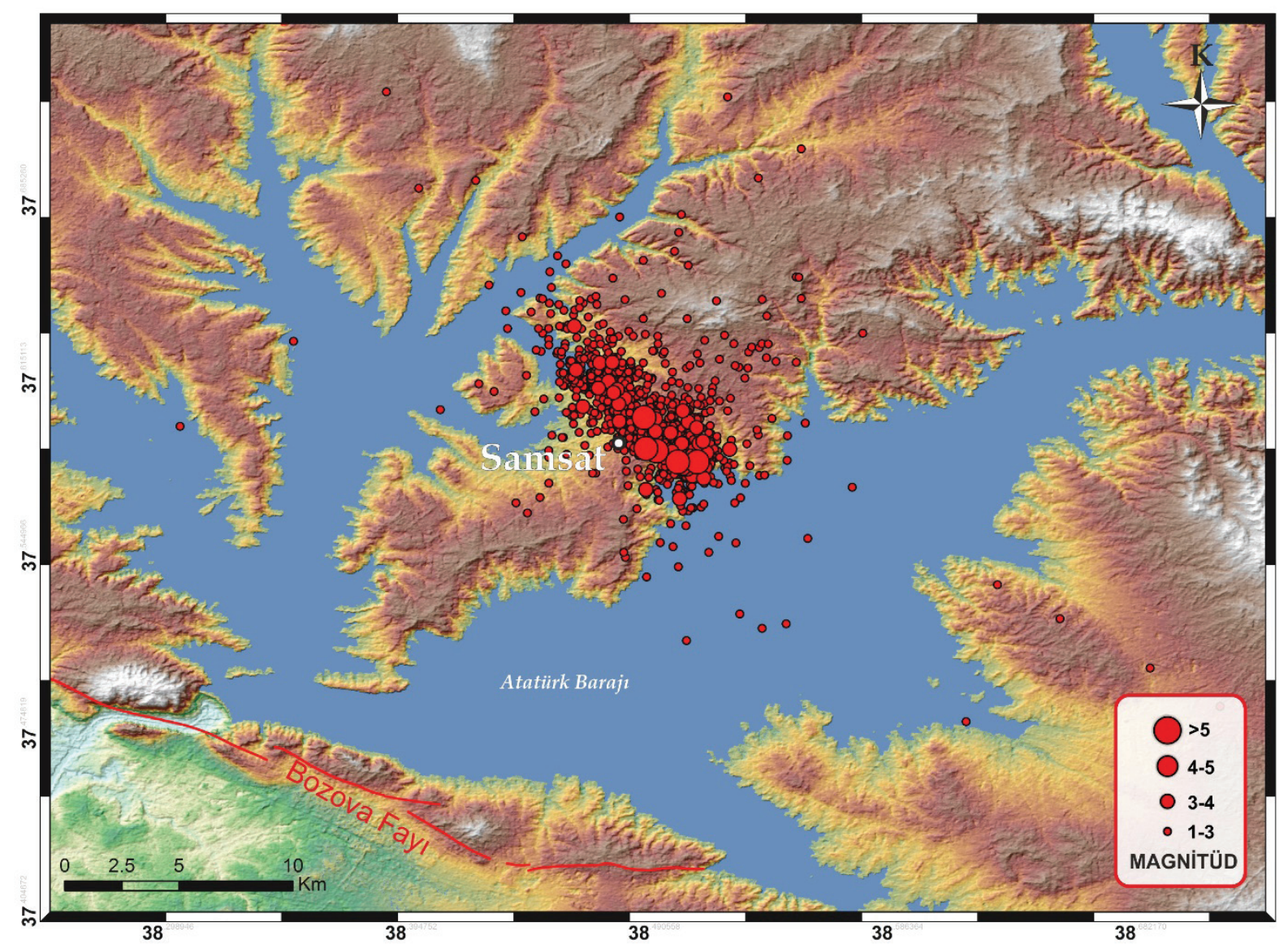

Şekil 3. Boğaziçi Üniversitesi Kandilli Rasathanesi ve Deprem Araştırma Enstitüsü, Ulusal Deprem Merkezi (UDIM)'nden alınan 2 Mart 2017 ve 24 Nisan 2018 Samsat Depremleri ve artçı sarsıntılarını gösterir sayısal yükselti modeli.

Figure 3. Main and aftershock distribution of 2 March 2017 and 24 April 2018 Samsat earthquakes from Bogazici University Kandilli Observatory and Earthquake Research Institute, National Earthquake Research Center (UDIM). 
2 Mart 2017 depreminden sonra bölgede yapılan saha çalışmalarında yıkımın Samsat ilçe merkezinin yanısıra, kuzeyinde yer alan Uzuntepe, Akdamar, Taşkuyu ve Tepeönü köylerinde yoğunlaştığı gözlenmiştir (Şekil 4). Deprem sonucunda herhangi bir yüzey faylanması gelişmemiştir. Ancak bazı alanlarda yer yer sistematik şekilde gelişmiş çatlakların varlığı dikkat çekmiştir. Bu çatlakların genel doğrultusu K40-50 B olarak ölçülmüştür. Deprem sonrası Akdamar ve Taşkuyu Köylerinde yapılan incelemelerde hasarın belli bir hat boyunca yoğunlaştığ1 gözlenmiştir. Akdamar Köyünde bir bahçe duvarında yaklaşık K50B gidişli sağ yanal doğrultu atımlı deformasyon izi belirgin şekilde izlenmiştir (Şekil 5).
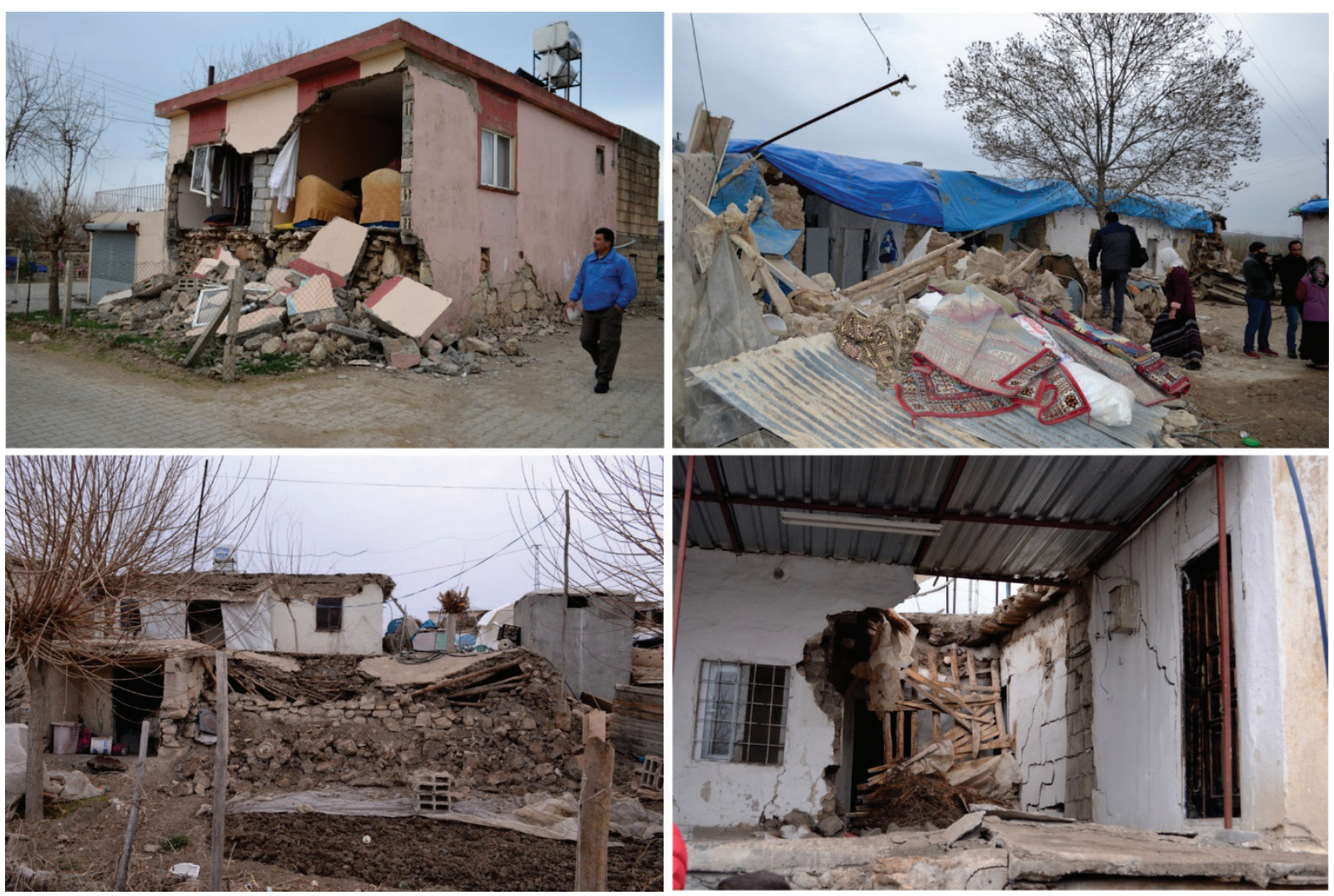

Şekil 4. 2 Mart 2017 depreminden sonra Samsat kuzeyinde Akdamar ve Taşkuyu köylerinde oluşan yapısal hasarlar. Figure 4. Structural damages in Akdamar and Taşkuyu villages located in north of Samsat after 2 March 2017 earthquake. 

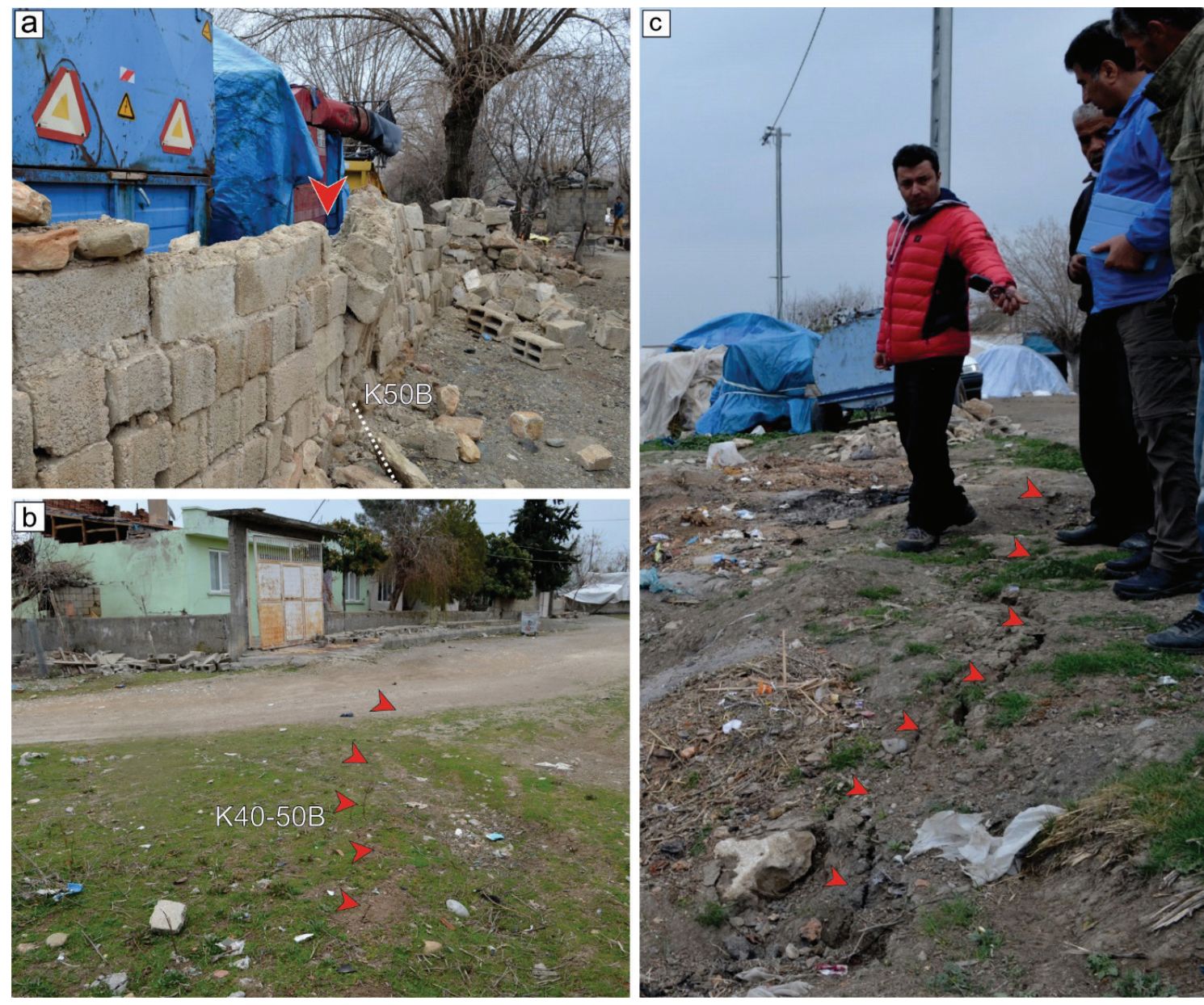

Şekil 5. 2 Mart 2017 depremi sonrası (a) Akdamar köyünde gözlenen sağ yanal doğrultu atımlı faylanmayı işaret eden çizgisellik, (b) Samsat ilçe merkezi ve (c) Taşkuyu köyünde gözlenen yüzey çatlakları.

Figure 5. (A) Lineament indicating right lateral strike-slip faulting observed in Akdamar village, surface cracks observed in (b) Samsat district center and (c) Taşkuyu village.

2 Mart 2017 tarihinde meydana gelen depremin bölgede yüzey deformasyonları oluşturup oluşturmadığı, Yapay Açıklık Radar İnterferometrisi (InSAR) yöntemiyle de incelenmiştir. InSAR yöntemi, yapay açıklık radarı (SAR) görüntüleri yardımı ile yeryüzünde meydana gelen deformasyonların oluşturduğu faz farklarını belirleyen yöntemdir. Bu amaçla, 2 Mart 2017 depremi sonrasında, inceleme alanı ve yakın çevresini içine alan Sentinel-1A radar görüntüleri analiz edilmiştir. Bu görüntülerin analiz edilmesi ile oluşturulan interferogram incelendiğinde, Samsat İlçe merkezinin kuzeydoğusunda faz değişimi (fringe) izlenmektedir. Şekil 6'da gösterilen interferogram 2 Mart 2017 Samsat depreminin deprem sonrasina ait (co-seismic) yüzey deformasyonunu gösteren Sentinel-1A interferogramıdır. Faz farkından oluşan saçakların genel dağılımına bakıldığında, en içteki ve en diştaki halka tek bir faza eşittir. Oluşan deformasyon saçak sayısı ile fazın çarpımına eşitti. Bu da bize uydu bakış yönünde (LOS) 2.78 cm'lik bir deformasyonun varlığını göstermektedir. $\mathrm{Bu}$ deformasyonların daha çok Samsat ilçesi yakın kuzeydoğusunda yoğunlaştığı görülmektedir. 


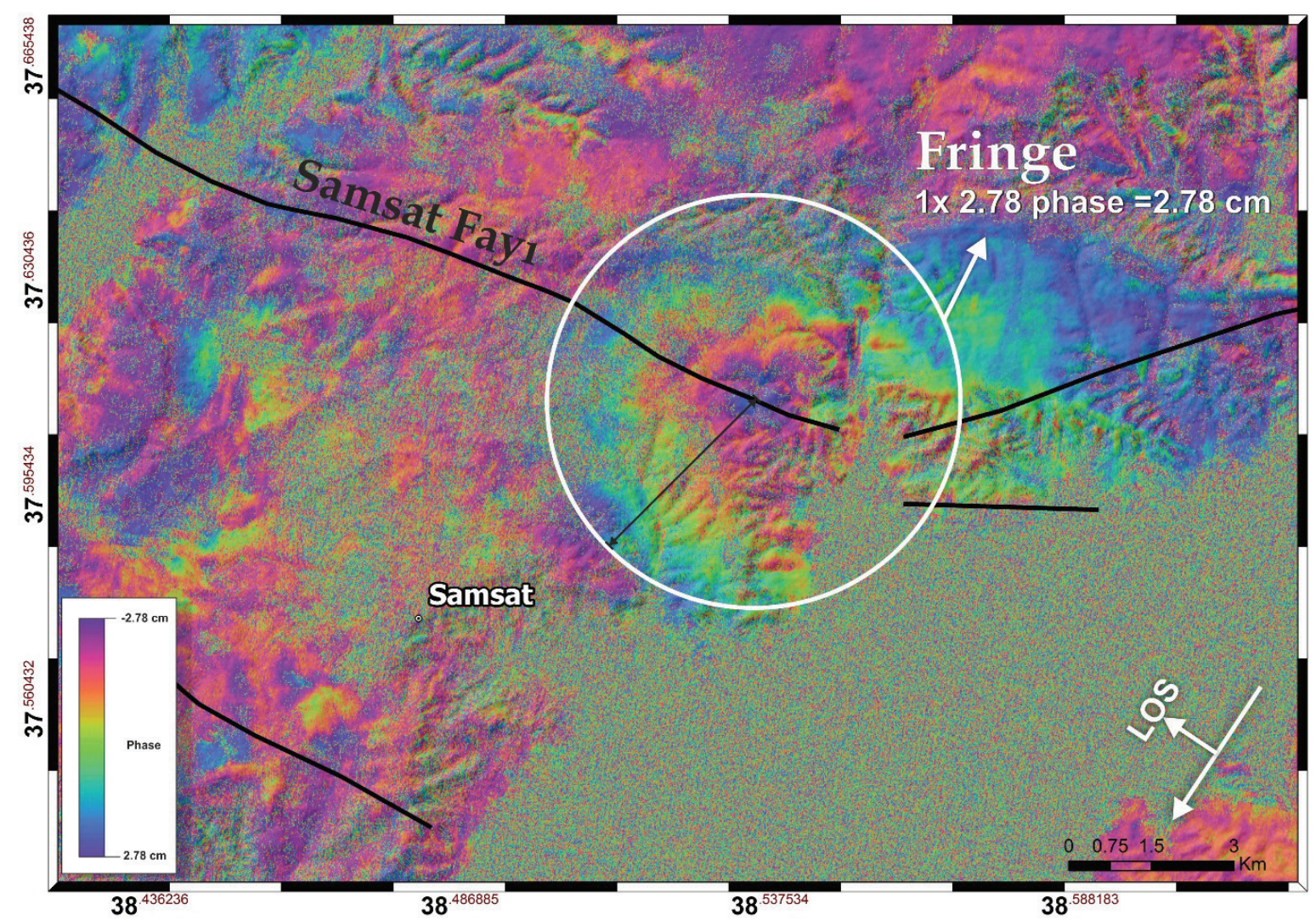

Şekil 6. 2 Mart 2017 Samsat depreminin deprem sonrası (co-seismic) yüzey deformasyonunu gösteren Sentinel-1A interferogrami.

Figure 6. Sentinel-1A interferogram showing the co-seismic surface deformation of March 2, 2017 Samsat earthquake.

\section{SONUÇLAR VE TARTIŞMA}

Seyitoğlu vd. (2017) Güneydoğu Türkiye, Kuzey Suriye ve Irak'in neotektoniğini konu alan çalışmalarında Güneydoğu Anadolu Kaması'nın içyapıs1, bölgedeki kör bindirmeler ve bunların güncel depremlerle ilişkisini ortaya koymuşlardır. Yazarlar, Türkiye»nin mevcut aktif fay haritasının (Emre vd. 2013), özellikle güneydoğu Türkiye tüm sismik olaylarla ilişkiyi açıklamadığını ifade etmektedir. Aktif fayların çoğu doğrultu atım özelliğine sahiptir ve Türkiye»nin doğusunda örneğin Çaldıran, Varto, Bingöl'de meydana gelen büyük depremlerden sonra varlığı ortaya konmuştur. Aktif bindirme fay hatları, Bitlis Kenet Kuşağı hariç, MTA diri fay haritasında nadiren gösterilmiş ve sınırlı tanımlama büyük olasılıkla bindirmeyle ilgili büyük depremlerden kaynaklanmış olan Van ve Cizre Faylarıdır. Örneğin 1975.09.06 Lice depremi (Ms: 6.7) Bitlis Kenet Kuşağı ile ilişkilendirilmiştir (Arpat, 1977; Jackson ve McKenzie, 1984). Van Fay Zonu ise, 23.10.2011 Van depreminden (Mw: 7.1) sonra (Zahrandik ve Sokos, 2011) tanınıp haritalanmıştır. $\mathrm{Bu}$ da bize, Türkiye'nin doğu / güneydoğusundaki kör bindirmelerin önemli sismik kaynaklar olduğunu ve bunların ayrıntılı araştırılması gerektiğini göstermiştir (Seyitoğlu vd. 2017). Benzer şekilde 2017 ve 2018 Samsat Depremlerine kaynaklık ettiği düşünülen K40-50 ${ }^{\circ} \mathrm{B}$ gidişli fay da Yenilenmiş Türkiye Diri Fay Haritası'nda bulunmamakla birlikte, 
TPAO tarafından bölgede yapılan çalışmalarda Samsat Fayı olarak adlandırılmış ancak fayın aktivitesi ile ilgili ayrıntılı bilgi verilmemiştir. Samsat güneyinde bulunan ve Türkiye Diri Fay Haritası'nda Kuvaterner yaşlı Bozova Fayı olarak tanımlanan fay ters bileşenli sağ yanal doğrultu atımlı bir fay özelliğindedir. 2 Mart 2017 ve 24 Nisan 2018 depremlerine kaynaklik ettiği düşünülen Samsat Fayının ise sağ yanal doğrultu atımlı özellikte olduğu düşünülmektedir. Gerek deprem sonrası sahada yapılan gözlemler ve gerekse her iki depremin odak mekanizması çözümleri bunu doğrulamaktadır.

Samsat ve civarındaki deprem aktivitesine Eyidoğan vd. 2010 farklı bir yaklaşımda bulunmuş ve Atatürk Barajı ve Hidroelektrik Santrali göl alanı içinde 3 Eylül 2008 tarihinde meydana gelen $\mathrm{Ml}=5.2$ büyüklüğündeki depremin ve sonrasında oluşan $\mathrm{Ml}=4.6$ ve $\mathrm{Ml}=4.0$ büyüklügüundeki iki artçı sarsıntının mekanizma özelliklerini incelemişlerdir. Yazarlar, 3 Eylül 2008 depreminin barajın su yükündeki değişimler tarafından tetiklendiğini ve Bozova fayı ile ilişkisinin olmadığını, baraj su seviyesinin radikal değişimlerinin sürmesi durumunda orta büyüklükteki depremlerin olabileceğini vurgulamışlardır. Eyidoğan ve Geçgel (2010) ise 1992-2009 yılları arasında Atatürk Barajındaki su değişimlerini inceleyerek bunun tetiklenmiş depremsellik ilişkisini tartışmışlardır. Elde ettikleri veriler, depremsellik dağılımı ve fay düzlemi çözümleri, tetiklenmiş depremselliğin üst kabukta ve KB-GD yönlü sağ-yanal doğrultu atım niteliğindeki faylanmalarla ilişkili olduğunu işaret etmektedir. Buna karşın 2 Mart 2017 ve 24 Nisan 2018 Samsat Depremlerinin oluşum mekanizması, sonrasında meydana gelen çok sayıda artçı deprem aktivitesi ve bu artçı sarsıntıların belli bir hat boyunca dizilim göstermesi, bu depremlerin Atatürk Baraj1 ve HES su alanındaki ani değişimlerle doğrudan ilişkisinin olmadığını ve bu depremlerin bölgedeki $\mathrm{K} 40-50^{\circ} \mathrm{B}$ gidişli Samsat Fayı ile ilişkili olduğunu ortaya koymaktadır.

\section{KATKI BELIRTME}

Bu çalışma 2 Mart 2017 tarihinde meydana gelen deprem sonrasında, AFAD Sivas İl Müdürlüğü’nün sağladığı lojistik destekle gerçekleştirilmiştir. Desteklerinden dolayı İl Müdürü Nazif Ekinci’ye teşekkür ederiz.

\section{EXTENDED SUMMARY}

According to AFAD data at 14.07 local time on March 2, 2017, Mw: 5.5 magnitude earthquake occurred in Uzuntepe Village of Samsat district of Adlyaman province. Around 30 people were injured after this earthquake and damage occurred in Samsat district center and surrounding villages. After more than a year, the earthquake occurred on April 24, 2018 at 03.34 local time in the same region. As a result of the earthquake, 35 people were slightly injured, 2 buildings were demolished and some buildings were damaged in light and medium size. Located in Southeastern Anatolia Region on the banks of the Euphrates River, Samsat is one of the oldest settlements in the region. Samsat, which is located in the widest part of the plain between Kâhta and Göksu Creeks on the banks of the Euphrates, was transformed into Adryaman, due to the fact that Adiyaman was a provincial center in 1954. This settlement, formerly called Samsat, was flooded in 1987 with the rise of the Atatürk Dam and the district was completely evacuated and moved to its present location in 1988 (Baklrcl 1997). It is one of the areas where the thrust tectonics is located between the Southeast Anatolian Thrust Zone and the left lateral strike-slip East Anatolian Fault Zone. Thrusting and left-lateral strike-slip fault systems as well as Bozova Fault located in the south of Samsat District shown on the updated Active Fault Map of Turkey (Duman et al. 2012). Bozova fault is described as the Quaternary Fault extending for about $50 \mathrm{~km}$ long, and as a right lateral strike slip fault with a reverse component on the seismotectonics map of Turkey (Duman et al. 2017). 
Earthquakes occurred in historical and instrumental periods in the region. Earthquakes in the region consist of two main sources. Destructive earthquakes occurred in the historical periods on the East Anatolian Fault Zone in the north-northwest of Samsat and the Southeast Anatolia Thrust Zone. While there were no historical earthquakes in Adlyaman between 1800 and 1900 BC, devastating earthquakes occurred

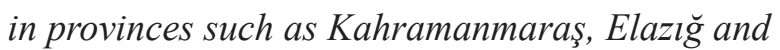
Malatya. Eyidoğan and Geçgel (2010) suggested that changes in the water level in the Atatürk Dam caused the triggered earthquake activity in the region. The authors stated that the earthquakes occurred in the Atatürk Dam Lake basin between 21.02.2008 (Mw:3.5) and 03.09.2008 (Mw:5.0) were caused by the oscillations and decreases in the water level.

The closest settlement to the epicenter of Mw:5.5 magnitude earthquake occurred on 02.03.2017 is Uzuntepe village located in the north of Samsat district. The focal depth of the earthquake lasting about 11 seconds is 9.76 $\mathrm{Km}$. Immediately after the earthquake, many aftershocks with magnitude up to 4.4 occurred and these shocks continued for a long time. The focal mechanism solution made by the AFAD Earthquake Department shows that the earthquake is formed on a right lateral strike-slip fault. Approximately 14 months after the earthquake in 2017, Mw $=5.1$ magnitude earthquake occurred on April 24, 2018 and the focal depth of the earthquake is around $13 \mathrm{~km}$. The epicenter of the earthquake falls to the village of Kirmacı, south of the Samsat district. After this earthquake, a large number of aftershocks were recorded, reaching a size of 3.6. The focal mechanism solution of the earthquake by the Kandilli Observatory and the Earthquake Research Institute shows a slightly biased right lateral strike-slip faulting mechanism dipping to the northeast. It is understood that the earthquakes occurred on March 2, 2017 and April 24, 2018 were slightly different when the fault plane solutions were compared. The earthquake on 2 March 2017 shows a right lateral strike-slip faulting mechanism, while the 24 April 2018 earthquake indicates right-lateral strike-slip faulting with a slightly reverse component. When the epicenters of both earthquakes were compared, it is seen that the epicenter of the 2017 earthquake fell to the north of Samsat and the 2018 earthquake fell to the south of Samsat. The distribution of aftershocks shows the concentration of roughly NW-SE lineament for both earthquakes. After the 2 March 2017 earthquake, it was observed that the damage was concentrated in the villages of Uzuntepe, Akdamar, Taşkuyu and Tepeönü to the north of the Samsat district center. No surface faulting occurred as a result of the earthquake. However, the presence of systematically developed surface cracks in some areas has attracted attention. The general direction of these cracks was measured as N40-50W.

Synthetic Aperture Radar Interferometry (InSAR) method was used to determine the possible surface deformation of the earthquake occurred on March 2, 2017. For this purpose, after the earthquake of March 2, 2017, Sentinel1 A radar images were taken into consideration. When the interferogram generated by analyzing these images is examined, it is observed that the fringe of the northeast of Samsat District is observed. N40-50W trending fault which utilizes the earthquakes in 2017 and 2018 faults is not shown in updated Active Fault Map of Turkey, but the studies conducted in the region by TPAO has called Samsat fault but no more detailed information about the fault activity.

\section{ORCID}

Orhan Tatar D https://orcid.org/0000-0001-9579-1607

Fikret Koçbulut (D) https://orcid.org/0000-0003-3578-029X Mehmet Demirel D https://orcid.org/0000-0002-4065-2420 


\section{DEĞINILILN BELGELER}

Ambraseys, N.N. (1988). Engineering seismology. Earthquake Engineering and Structural Dynamics 17, 1-105.

Ambraseys, N.N. ve Jackson, J.A. (1998). Faulting associated with historical and recent earthquakes in the Eastern Mediterranean region. Geophysical Journal International, 133, 390-406.

Arpat, E. (1977). 1975 Lice Depremi. Yeryuvarı ve İnsan. S. 15-27.

Bakırcı, M. (1997). Türkiye'de yer değiştiren şehirlere yeni bir örnek: Samsat. Türk Coğrafya Dergisi, Say1 32, s.365-391.

Duman, T.Y., Emre, Ö., Özalp, S., Olgun, Ş. ve Elmacı, H. (2012). 1:250.000 ölçekli Türkiye Diri Fay Haritası Serisi, Şanlıurfa (NJ 37-10) ve Suruç (NJ 37-14) Paftaları. Seri No 43, Maden Tetkik ve Arama Genel Müdürlüğü, Ankara.

Duman, T.Y. ve Emre, Ö. (2013). The East Anatolian Fault: geometry, segmentation and jog characteristics. Geological Society of London, Special Publications No 372. In: Robertson, A.H.F., Parlak, O. ve Ünlügenç, U.C. (eds) Geological Development of Anatolia and the Easternmost Mediterranean Region.

Duman, T.Y., Emre, Ö., Özalp, S., Çan, T., Olgun, Ş., Elmac1, H. ve Şaroğlu, F. (2017). Türkiye ve Yakın Çevresindeki Diri Faylar ve Özellikleri. Türkiye Sismotektonik Haritası Açıklama Kitabı, (Ed. T.Y. Duman). Maden Tetkik ve Arama Genel Müdürlüğü Özel Yayınlar Serisi-34, 12 s. AnkaraTürkiye.

Emre, Ö., Duman, T.Y., Elmac1, H., Özalp, S. ve Olgun, Ş. (2012). 1:250.000 Ölçekli Türkiye Diri Fay Haritası Serisi, Malatya (NJ 37-6) Paftas1, Seri No: 45, Maden Tetkik ve Arama Genel Müdürlüğü, Ankara-Türkiye.

Eyidoğan, H. ve Geçgel, V. 2010. Atatürk Baraj1 Su Düzeyi ve Tetiklenmiş Depremsellik İlişkileri. 1992-2009. Aktif Tektonik Araştırma Grubu 14. Çalıştayı, Bildiri Özleri Kitapçı̆̆ı̆, s.31, Adıyaman Üniversitesi.

Eyidoğan, H., Geçgel, V. ve Pabuçcu, Z. (2010). 3 Eylül 2008 Atatürk Barajı Depremi: Tetiklenmiş Depremsellik ve Bozova Fayı. Türkiye Jeoloji Kurultayı, Bildiri Özleri Kitapçı̆̆ı
Gökçe, O., Tüfekçi, M.K. ve Gürboğa, Ş. (2014). Yüzey Faylanması Tehlikesinin Değerlendirilmesi ve Fay Sakınım Bantlarının Oluşturulması. Afet ve Acil Durum Yönetimi Başkanlığı Yayınları, 387 s., Ankara.

Gülkan, P. Yücemen, M.S., Başöz, N. Koçyiğit, A. ve Doyuran, V. (1993). En Son Verilere Göre Hazırlanan Türkiye Deprem Bölgeleri Haritas1. Orta Doğu Teknik Üniversitesi, İnşaat Mühendisliği Bölümü, Deprem Mühendisliği Araştırma Merkezi, Rapor No. 93-01, Ocak.

Herece, E. (2008). Doğu Anadolu Fayı (DAF) Atlası. General Directorate of Mineral Research and Exploration. Special Publications, Ankara, Serial Number, 13, 359.

İmamoğlu, M. Ş. ve Çetin, E. (2007). Güneydoğu Anadolu Bölgesi ve yakın yöresinin depremselliği. D.Ü. Ziya Gökalp Eğitim Fakültesi Dergisi, 9, 93103.

Jackson, J. and McKenzie, D. (1984). Active tectonics of the Alpine-Himalayan Belt between western Turkey and Pakistan. Geophys J R Astr Soc Lond 77: 185-264.

Ketin, İ. (1966). Anadolu'nun tektonik birlikleri. Maden Tetkik Arama Ens. Dergisi, 66, 20-34.

Perinçek, D. (1978). Çelikhan-Sincik-Koçali (Adıyaman İli) alanının jeolojik incelenmesi ve petrol olanaklarının araştırılması. IÜFF Tatbiki Jeoloji Kürsüsü, Doktora tezi, TPAO Arama Grubu, Rapor no. 1250, 212 s., Ankara.

Sbeinati, M.R., Darawcheh, R. ve Mouty, M. (2005). The historical earthquakes of Syria: an analysis of large and moderate earthquakes from 1365 B.C. to 1900 A.D. Annals of Geophysics, Vol. 48, N 3, pp. 347-435.

Seyitoğlu, G., Esat, K. ve Kaypak, B. 2017. The neotectonics of southeast Turkey, northern Syria and Iraq: the internal structure of the Southeast Anatolian Wedge and its relationship with recent earthquakes. Turkish J Earth Sci, 26: 105-126.

Şengör, A.M.C. ve Yılmaz, Y. (1981). Tethyan evolution of Turkey: a plate tectonic approach. Tectonophysics 75, 181-241.

Yıldırım, N. (2012). Havza-Kuşak madenciliği kapsamında keşfedilen Güneydoğu Anadolu Kıbrıs tipi VMS metalojenik kuşağı: Koçali 
Karmaşığı, Adıyaman Bölgesi, Türkiye. MTA Doğal Kaynaklar ve Ekonomi Bülteni, Sayı 14, s.47-55.

Yilmaz, Y. (1990). Comparison of young volcanic associations of western and eastern Anatolia formed under a compressional regime: a review. Journal of Volcanology and Geothermal Research, 44 (1-2), 69-87.

Y1lmaz, Y. (1993). New evidence and model on the evolution of the southeast Anatolian orogen. Bull. Geol. Soc. Am., 105.
Yılmaz, Y., Yiğitbaş, E., Yıldırım, M. ve Genç, Ş.C. (1992). Güneydoğu Anadolu metamorfik masiflerinin kökeni. Türkiye 9. Petrol Kongresi Bildirileri, 296-306, Ankara.

Yılmaz, Y., Yiğitbaş, E. ve Genç, Ş.C. (1993). Ophiolitic and metamorphic assemblages of southeast Anatolia and their significance in the geological evolution of the orogenic belt. Tectonics, 12, p. 1280-1297.

Zahradnik, J. and Sokos, E. (2011). Multiple-point source solution of the $\mathrm{Mw} 7.2$ Van earthquake, October 23, 2011, Eastern Turkey. Report submitted to EMSC on November 1, 2011. 